\title{
Upregulation of microRNA-300 induces the proliferation of liver cancer by downregulating transcription factor FOXO1
}

\author{
YUANHONG CHANG ${ }^{1,2}$, CANCAN ZHOU $^{3}$, LIN FAN $^{4}$, GUANGLIN QIU ${ }^{4}$, GUANGHUI WANG $^{4}$, \\ GUANGBING WEI ${ }^{4}$, XINMING $\mathrm{CHANG}^{1}$ and $\mathrm{XUQI} \mathrm{\textrm {LI } ^ { 4 }}$ \\ ${ }^{1}$ Department of Gastroenterology, The First Affiliated Hospital of Xi'an Jiaotong University, Xi'an, Shaanxi 710061; \\ ${ }^{2}$ Xi'an No. 4 Hospital, The Affiliated Guangren Hospital, School of Medicine, Xi'an Jiaotong University, \\ Xi'an, Shaanxi 710004; Departments of ${ }^{3}$ Hepatobiliary Surgery and ${ }^{4}$ General Surgery, \\ The First Affiliated Hospital of Xi'an Jiaotong University, \\ Xi'an, Shaanxi 710061, P.R. China
}

Received December 14, 2017; Accepted September 13, 2018

DOI: $10.3892 /$ or.2018.6727

\begin{abstract}
In the present study, we investigated whether miRNA-300 (miR-300) is an oncogene in human liver cancer and sought to determine the mechanism underlying its activity. We also investigated the effect of miRNA-300 on the growth in liver cancer. To identify its target molecule, we performed luciferase assays. The downstream signaling pathway was detected by immunohistochemical (IHC) analysis in human HCC tissues, and the protein levels of AKT, 4E-BP1, S6K1, SNAIL and MMP2 were determined using western blotting. miR-300 levels were higher in patients with high-stage HCC, and miR-300 promoted cell growth both in vitro and in vivo. miRNA-300 inhibited the luciferase activity of FOXO1 by targeting its 3'-untranslated region (UTR), and overexpression of miR-300 upregulated the protein levels of phospho-AKT, phospho-4E-BP1, phospho-S6K1, SNAIL and MMP2. These data revealed that miRNA-300 functions as an oncogene in liver cancer by inhibiting FOXO1 and interacting with the AKT/mTOR signaling pathway.
\end{abstract}

\section{Introduction}

Hepatocellular carcinoma (HCC) is the fifth most common malignancy in the world and the second most common cause of cancer-related death, according to the World Health Organization data $(1,2)$. Despite the fact that significant advances have been made in its diagnosis and its treatment options, which include new chemotherapeutic interventions and targeted therapies, patients with HCC display poor

Correspondence to: Dr Xuqi Li, Department of General Surgery, The First Affiliated Hospital of Xi'an Jiaotong University, 277 West Yanta Road, Xi'an, Shaanxi 710061, P.R. China

E-mail: lixuqi@163.com

Key words: microRNA-300, liver cancer, forkhead transcription factor, proliferation, migration long-term survival due to its high rates of intrahepatic and distal metastases (3). Signaling pathways such as the phosphoinositide 3-kinase (PI3K)/AKT signaling pathway have been implicated in HCC progression (4). PI3K/AKT pathway activation contributes to the progression and development of HCC and regulates the malignant biological functions of cancer cells (5). Thus, it is crucial to identify the mechanisms that underlie HCC progression and metastasis since these data could provide the field with new targets for cancer therapies.

MicroRNAs (miRNAs) are a group of endogenous, evolutionarily conserved, noncoding small RNAs that bind to their complementary sequence within the target mRNA 3'-untranslated region (UTR) to post-transcriptionally affect gene initiation and development and gene expression progression. miRNAs then induce target mRNA degradation or inhibit translation (6,7). A large amount of evidence indicates that abnormal miRNA expression plays key roles in many aspects of the progression of $\mathrm{HCC}(8,9)$. In particular, miRNAs display effects on cell proliferation, cell migration, cell apoptosis, drug resistance, and cell renewal. Recent studies have used genome-wide methods to show that miRNAs such as miR-129-2 (10), miR-124 (11), miR-203 (12) and miR-125b (13) are involved in HCC. miR-122 has important effects on the biology of HCC (14) and is also related to certain liver diseases. It is worth noting that HCC expresses some small RNAs. miRNAs have been identified as candidate biomarkers for HCC diagnosis and treatment and bind to some of the target molecules involved in various biological processes associated with HCC development (including cell proliferation, cell differentiation, cell apoptosis, and metastasis) or act as tumor suppressors $(15,16)$. Our aim was to identify the functions and mechanisms of the activities of key miRNAs in liver cancer, as these data may contribute to the development of methods for providing more accurate diagnoses or predicting outcomes in patients with liver cancer. One miRNA, miR-300, is highly expressed in HCC, but its potential role in the carcinogenesis and tumor development in liver cancer is unclear.

An increasing amount of evidence indicates that the poor prognoses and treatment failures of HCC are associated with the abnormal activation of many signaling pathways. Of 
these, the PI3K/AKT signaling pathway is the most important pathway through which cells regulate malignancy (17). It is worth noting that abnormal Akt activation is an undesirable prognostic factor in all stages of $\mathrm{HCC}$ and contributes to resistance to single first-generation targeted therapies. Akt and protein kinase B (57-kDa Ser/Thr kinase) are activated by extracellular signalling. Akt is often activated in cancer cells and subsequently activates cell proliferation and induces immune cell apoptosis (18). However, Akt over-activation increases intracellular ROS levels by increasing oxygen consumption and inhibits ROS scavengers downstream of forkhead transcription factor (FOXO). Akt also induces premature senescence and sensitizes cells to ROS-mediated apoptosis (19). FOXO1, a member of the FOXO subfamily that plays an important role in protecting cells from the microenvironment, is directly phosphorylated by Akt, resulting in the inhibition of its transcriptional activity. Thus, inhibitors that target these pathways may be potent therapeutic agents in cancer.

In the present study, we showed that miR-300 is highly expressed in HCC tissues and induces the downregulation of FOXO1, which leads to the downregulation of the AKT/FOXO1 pathways, resulting in the accelerated proliferation and migration of HCC and liver cancer cells.

\section{Materials and methods}

Clinical tissues. From January 2012 to December 2013, liver tissues were collected from 36 patients with HCC and normal liver tissues from 18 patients at the Department of Hepatobiliary Surgery at the First Affiliated Hospital of Xi'an Jiaotong University. The tissues were stored at $-80^{\circ} \mathrm{C}$ or embedded in paraffin. No chemotherapy or radiotherapy was administered to any of the included patients before surgery.

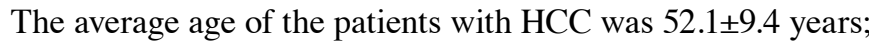
the study population included 30 males and 6 females. A total of 26 patients were positive for hepatitis B virus. According to the TNM classification system (20), 12 patients had stage I disease, 6 patients had stage II disease, 14 patients had stage III disease, and 4 patients had stage IV disease. Ethical approval for the study was obtained from the First Affiliated Hospital Ethics Committee of Xi'an Jiaotong University. All participants provided written informed consent.

Cell culture and reagents. The human HCC cell lines HCCLM3, HuH-7 and SK-HEP1, and liver cancer Hep3B, HepG2 and HuH-6 cells were obtained from the Shanghai Institutes for Biological Sciences (SIBS) of the Chinese Academy of Sciences (CAS), and the HCC cell lines MHCC97-H and MHCC97-L were obtained from Fudan University (Shanghai, China). The cells were cultured in Invitrogen ${ }^{\mathrm{TM}}$ RPMI-1640 medium (Thermo Fisher Scientific, Inc., Waltham, MA, USA) with $10 \%$ fetal bovine serum (FBS; BioWest, Nuaillé, France) and $1 \%$ penicillin-streptomycin (Sigma-Aldrich; Merck KGaA, Darmstadt, Germany) at $37^{\circ} \mathrm{C}$ in a humidified atmosphere of $5 \% \mathrm{CO}_{2}$.

Rapamycin was obtained fromSigma-Aldrich/MerckKGaA and dissolved in DMSO. The Akt inhibitor AZD5363 (cat. S8019) was purchased from Selleck Chemicals (Houston, TX, USA). Phosphatidylinositol 3'-kinase (PI3K) inhibitor
(LY294002, cat. BML-ST420-0025) was purchased from Alexis Biochemicals (San Diego, CA, USA).

Quantitative reverse-transcriptase polymerase chain reaction $(q R T-P C R)$. Total RNA was isolated from HCC tissues or HCC/liver cancer cells using TRIzol reagent (Invitrogen; Thermo Fisher Scientific, Inc.), according to the manufacturer's instructions. Two micrograms of total RNA were reverse transcribed into cDNA using a reverse transcription kit (Takara Bio, Inc., Tokyo, Japan). Then, the cDNA was amplified using a SYBR ${ }^{\circledR}$ Premix Ex Taq ${ }^{\mathrm{TM}}$ II (Perfect Real-Time) Kit (Takara, Bio). The following PCR primers were used: 5'-GGATGT GCATTCTATGGTGTACC-3' (forward) and 5'-TTTCGG GATTGCTTATCTCAGAC-3' (reverse) for FOXO1 (86 bp) and 5'-CTCACCGGATGCACCAATGTT-3' (forward) and 5'-CGCGTTGCTCACAATGTTCAT-3' (reverse) for GAPDH (82 bp). qRT-PCR included an initial denaturation cycle at $95^{\circ} \mathrm{C}$ for $2 \mathrm{~min}$, followed by 35 cycles of denaturation at $98^{\circ} \mathrm{C}$ for $10 \mathrm{sec}$ and annealing and extension at $60^{\circ} \mathrm{C}$ for $45 \mathrm{sec}$. Gene expression levels were calculated through the $\Delta \Delta \mathrm{Ct}$ method; U6 (miRNA detection) or GAPDH (mRNA detection) was used as an internal control. The hsa-miR-300 primer (HmiRQP0377) and snRNA U6 qPCR primer (HmiRQP9001) were obtained from GeneCopoeia (Guangzhou, China). The results are expressed as the mean value of three independent experiments.

Cell transfection. miRNA vectors, including precursor miR-300 clones (miR-300, HmiR0490), and an miR-300 inhibitor (anti-miR-300; HmiR-AN0377) and miR-300 inhibitor control clone (anti-miR-con, CmiR-AN0001) were purchased from GeneCopoeia (Guangzhou, China). Plasmids containing the FOXO1 gene, specific siRNA for FOXO1 (sense, 5'-CCAUGG ACAACAACAGUAA-3'; antisense, 5'-CCAUGGACAACA ACAGUAA-3') or scrambled siRNA (sense, 5'-UCACAACCU CCUAGAAAGAGUAGA-3'; antisense, 5'-UACUCUUUC UAGGAGGUUGUGAUU-3') for FOXO1 were synthesized by Bioworld Biotech Co., Ltd. (Shanghai, China). Cells were transfected with the above vectors by Lipofectamine 3000 (Invitrogen; Thermo Fisher Scientific, Inc.), according to the manufacturer's protocol. Transfected cells were harvested at $24 \mathrm{~h}$ or the indicated time for qRT-PCR or western blot analysis.

MTT assay. Cells were analyzed with the 3-(4,5-dimethylthiazol-2-yl)-2,5-diphenyltetrazolium bromide (MTT) method to detect cell viability. The target cells were transfected with miR-300, miR-con, anti-miR-300 or anti-miR-con using Lipofectamine. Briefly, 5,000 cells were seeded in each well and cultured in a cell incubator for the indicated times (24, 48, 72 and $96 \mathrm{~h})$. Then, $10 \mu \mathrm{l}$ of MTT $(5 \mathrm{mg} / \mathrm{ml}$ diluted in 1X PBS) was added to each well, and the cells were incubated for an additional $4 \mathrm{~h}$ at $37^{\circ} \mathrm{C}$. After incubation, $100 \mu \mathrm{l}$ of DMSO was added to the wells to dissolve the crystals. Then, the absorbance of each well in the culture plates was measured at $450 \mathrm{~nm}$ with a micro-plate reader (Bio-Rad Laboratories, Hercules, CA, USA) after the plates were oscillated for $10 \mathrm{~min}$ at room temperature (RT).

Preparation of the cell extracts and western blot analysis. Whole protein was lysed in RIPA buffer supplemented with 
protease (Roche, Manheim, Germany) and phosphatase (Roche) inhibitors, and then the protein concentration was quantified with a BCA Protein Assay Kit (Qiagen, Valencia, CA, USA), according to the manufacturer's protocol. The protein samples $(40 \mu \mathrm{g})$ were digested, run on $10 \%$ SDS-PAGE gels, and then transferred to PVDF membranes (Millipore, Billerica, MA, USA), which were blocked in 5\% skim milk in $1 \mathrm{X}$ TBST for $2 \mathrm{~h}$ at RT and incubated in primary antibodies overnight at $4^{\circ} \mathrm{C}$. The membranes were then washed three times in $1 \mathrm{X}$ TBST and incubated with HRP-conjugated secondary antibodies (goat anti-rabbit IgG-HRP, 1:10,000 dilution; cat. no. ab6721; goat anti-mouse IgG-HRP, 1:10,000 dilution; cat. no. ab6789; Abcam, Cambridge, MA, USA) at RT for $2 \mathrm{~h}$. The assay was performed using an enhanced chemiluminescence kit (Amersham, Little Chalfont, UK). GAPDH (1:2,000 dilution; cat. no. ab8245; Abcam) was used as a protein loading control. The FOXO1 primary antibody was obtained from Abcam (1:1,000 dilution; cat. no. ab52857) and total AKT (tAKT; 1:500 dilution; cat. no. 4691), phospho-AKT (pAKT, 1:500 dilution; cat. no. 4060), total 4E-BP1 (t4E-BP1, 1:1,000 dilution; cat. no. 9644), phospho-4E-BP1 (p4E-BP1, 1:500 dilution; cat. no. 2855), total S6K1 (tS6K1; 1:1,000 dilution; cat. no. 2708), phospho-S6K1 (pS6K1, 1:500 dilution; cat. no. 9208), SNAIL (1:1,000 dilution; cat. no. 3879) and MMP2 (1:1,000 dilutio; cat. no. 40994) antibodies were purchased from Cell Signaling Technology, Inc. (Beverly, MA, USA).

Cell migration and invasion assays. Matrigel-uncoated and -coated Transwell inserts $(8-\mu \mathrm{m}$ pore size; Corning Inc., Corning, NY, USA) were used to assess HCC and liver cancer cell migration and invasion in vitro. Briefly, $2 \times 10^{5}$ transfected cells were suspended in $150 \mu \mathrm{l}$ of serum-free DMEM and placed in the upper chamber, and $700 \mu \mathrm{l}$ of $20 \%$ FBS containing DMEM was loaded into the lower chamber. After $24 \mathrm{~h}$ of incubation, the cells were fixed in $4 \%$ paraformaldehyde for $20 \mathrm{~min}$ and then stained with $0.1 \%$ crystalline violet dye for $15 \mathrm{~min}$. The non-migrating or invading cells were gently removed using a cotton swab. The mean number of migrated or invaded cells was determined by averaging the numbers of cells in 10 fields in both inserts with ImageJ software (National Institutes of Health, Bethesda, MD, USA). All experiments were performed in duplicate and repeated at least three times.

Wound healing assay. Wound healing assay was performed to examine cell migration capacity. The cells were seeded in 24-well plates at a density of $1.2 \times 10^{5}$ cells/well; they were cultured in complete medium and grown to $80 \%$ fusion. The cells were then transfected with $50 \mathrm{nM}$ miR-300 or anti-miR-300 and/or treated with target FOXO1/siFOXO1. After $24 \mathrm{~h}$, the transfection medium was replaced with fresh medium. When the cells reached $100 \%$ confluence, a sterile micropipette was used to scratch the cell layer. After the cells were washed with PBS, serum-free medium was added to the wells. Images were captured immediately after the plates were scratched and $24 \mathrm{~h}$ later to monitor cell migration toward the injured area with a Zeiss microscope (Carl Zeis, Oberkochen, Germany). The migratory capability of the cells was quantified via measurements of the scratch area using ImageJ software (National Institutes of Health). The experiment was carried out twice.

Anchorage-independent growth ability (soft agar) assay. Cells $\left(4 \times 10^{3}\right)$ were suspended in $2 \mathrm{ml}$ of complete medium and $0.3 \%$ agar (Sigma-Aldrich; Merck KGaA). The agar/cell mixture was placed on top of a bottom layer containing a $1 \%$ mixture of complete medium and agar. After the cells were incubated for 10 days, the sizes of the colonies were measured using an eye micrometre, and colonies with a diameter $>0.1 \mathrm{~mm}$ were counted. The number of colonies of each cell line was manually counted in triplicate under an inverted microscope (Nikon Eclipse Ti-S; Nikon, Tokyo, Japan).

Luciferase reporter assay. $\mathrm{miR}-300$ is predicted to interact with the 3'-UTR sequence of FOXO1 by binding to the corresponding target sequence or a mutated sequence within the predicted target site. Therefore, the normal 3'-UTR and a mutated 3'-UTR were inserted into the pmiR-GLO double luciferase miRNA target expression vector (Promega, Madison, WI, USA); the resulting plasmids were called FOXO1 WT 3'-UTR and FOXO1 Mut 3'-UTR, respectively. Cells were seeded in 24-well plates and transfected with the FOXO1 WT 3'-UTR or FOXO1 Mut 3'-UTR vector using Lipofectamine. After $48 \mathrm{~h}$, the cells were harvested and analyzed according to the manufacturer's instructions (Dual-Luciferase Assay System; Promega). PRL-TK was used to express Renilla luciferase as an internal control and was co-transfected according to the correct transfection and harvest efficiencies.

Tumor sphere culture. Cancer cells were washed and subjected to enzymatic dissociation to single cells. Afterward, single cancer cells were re-suspended in tumor sphere media (TSM) consisting of serum-free DMEM, $20 \mathrm{ng} / \mathrm{ml}$ human recombinant epidermal growth factor (Sigma-Aldrich; Merck KGaA), $10 \mathrm{ng} / \mathrm{ml}$ human recombinant basic fibroblast growth factor-basic (R\&D Systems, Minneapolis, MN, USA) and $10 \mathrm{ng} / \mathrm{ml}$ epidermal growth factor (R\&D Systems). Cells were plated at a density of $7.5 \times 10^{4}$ to $1 \times 10^{5}$ cells $/ 10-\mathrm{mm}$ dish, and the medium was changed every other day until the tumor sphere formation was observed.

In vivo experiment. Sixteen male BALB/c nude mice aged 5 weeks (18-20 g) were purchased from the Shanghai Experimental Animal Center of the Chinese Academy of Sciences (Shanghai, China). The animals were maintained under specific pathogen-free (SPF) conditions at Xi'an Jiaotong University. The specific housing conditions were as follows: Temperature, $21 \pm 2^{\circ} \mathrm{C}$; humidity, $30-70 \%$; 12-h light/dark cycle; the ingested food and water were sterile feed and sterilized bottled water. All animal studies were performed according to the guidelines of the Institutional Animal Care and Use Committee of Xi'an Jiaotong University. Liver cancer cells HepG2 or HepG2-miR-300 were used for the tumor studies. Six mice were randomly assigned to each of the following groups. HepG2 and HepG2-miR-300 cells were harvested ( $2 \times 10^{6}$ cells per well), resuspended in $100 \mu \mathrm{l}$ of PBS, and then implanted subcutaneously into the flanks of BALB/c nude mice. The resulting tumors were designated either as HepG2 or HepG2-miR-300 tumors, respectively, and were monitored 
every day and measured every 2 days with a Vernier calliper to record the diameter. Tumor volume $(\mathrm{V})$ was calculated with the following formula: $\mathrm{V}=\mathrm{W}^{2} \times \mathrm{L} / 2$, where $\mathrm{L}$ is the length, and $\mathrm{W}$ is the width of the tumor. On the 24th day after tumor injection, the experimental animals were sacrificed via $\mathrm{CO}_{2}$ inhalation according to the animal care guidelines, and the tumors were removed for subsequent analyses. This experiment was conducted at the Xi'an Jiaotong University Experimental Research Laboratory with the consent of the Experimental Animal Ethics Committee (no. XJTULAC2018-450).

Immunohistochemical (IHC) analysis. Briefly, 4- $\mu$ m-thick slices were deparaffinized in xylene and dehydrated in fractional ethanol. Endogenous peroxidase activity was blocked by incubating the sections in 3\% hydrogen peroxide at RT for $10 \mathrm{~min}$. The appropriate antibody (1:200) was used as the primary antibody for the IHC analysis and was detected with the streptavidin peroxidase conjugation (SP-IHC) method. The semi-quantitative results were analyzed according to the staining intensity and the percentage of positively labelled cells as described by Sinicrope et al (21). Ten independent fields in each section were analyzed using ImageJ software (National Institutes of Health) at high magnification (x400) to obtain an average score.

Statistical analysis. The results are expressed as the mean \pm standard deviation and were calculated using data from at least three independent repetitions. SPSS 16.0 software (SPSS, Inc., Chicago, IL, USA) and GraphPad Prism 6.0 (GraphPad Software, Inc., La Jolla, CA, USA) were used to perform two-tailed Student's t-tests and Pearson's correlation analyses. One-way and two-way analysis of variance (ANOVA) were used to test for overall differences. Differences were defined as significant at $\mathrm{P}<0.05$.

\section{Results}

Aberrant miR-300 expression in human HCC and liver cancer cells is correlated with a poor prognosis. First, we detected miR-300 levels in HCC and liver cancer cells (HCCLM3, MHCC-97H, MHCC-97L, HuH-6, HuH-7, Hep3B and SK-HEP1) and normal liver cells (HL7702). As shown in Fig. 1A, miR-300 was expressed at higher levels in the liver cancer cells (Fig. 1A) than that in the normal liver cells (HL7702). These results indicate that $\mathrm{miR}-300$ is associated with liver cancer cell growth. We measured the expression of miR-300 in $54 \mathrm{HCC}$ tissue samples to verify that miR-300 is related to the development of HCC. miR-300 was expressed at significantly higher levels in HCC tissues than that noted in the normal liver tissues (Fig. 1B). Notably, miR-300 levels were highest in stage III-IV tumors and were higher in stage I-II tumors than in normal liver tissues (Fig. 1B), demonstrating that aberrant miR-300 expression in human HCC cells is correlated with a poor prognosis.

Effects of exogenous miR-300 on colony formation and cell viability in HCC cells. To better understand the function of miR-300 in HCC, we used lentiviral vectors to overexpress or silence miR-300 in the HCC cell lines. The expression levels of miR-300 in the resulting overexpression and knockdown cell lines were detected with qRT-PCR (data not shown). First, we used colony formation and MTT assays to investigate the growth-promoting effect of miR-300 on the HCC cell lines. The colony formation efficiency of the HCC MHCC-97L cells was $187.9 \pm 19.5$ in the miR-300 group and $92.1 \pm 7.9$ in the control group $(\mathrm{P}<0.05$, Fig. $2 \mathrm{C})$. In contrast, downregulating miR-300 reduced the proliferative ability of the HCCLM3 and MHCC97H cells. The colony formation efficiency of the HCCLM3 cells was 37.7 \pm 5.5 in the anti-miR-300 group and $117.5 \pm 12.1$ in the anti-miR-con group $(\mathrm{P}<0.05$, Fig. 2D), and the colony formation efficiency of the MHCC-97H cells was $110.0 \pm 15.5$ in the anti-miR-300 group and 54.0 \pm 7.6 in the anti-miR-con group $(\mathrm{P}<0.05$, Fig. $2 \mathrm{D})$. The MTT assays showed similar results (Fig. 2A). Thus, miR-300 significantly increased the viability of human HCC cells.

miR-300 promotes migration, invasion and sphere formation in HCC cells. To further explore the functions of miR-300 in HCC, we examined the effect of miR-300 on HCC cell migration and invasiveness. In our wound healing experiments, overexpression of miR-300 significantly accelerated wound healing in the HCC cells (Fig. 3A), while silencing of miR-300 reduced cell mobility (Fig. 3B). We also used a Transwell chamber whose inserts were coated with or without Matrigel to assess the invasive capacity of the HCC cells; the experimental results revealed that overexpression of miR-300 significantly enhanced the rate of HCC cell invasion (Fig. 3C), while silencing of miR-300 reduced the rate of HCC cell invasion (Fig. 3D).

We demonstrated that miR-300 is expressed at higher levels in HCC tissues (Fig. 1B). Sphere formation was analyzed to confirm the role of miR-300 in HCC cells. As shown in Fig. 4A, ectopic miR-300 expression promoted an increase in the number of HCC cell spheres (Fig. 4A), while silencing of miR-300 reduced sphere formation (Fig. 4B).

FOXO1 is a potential target of miR-300, and FOXO1 levels are inversely correlated with miR-300 levels in HCC tissues. The TargetScan and RNAhybrid algorithms predicted that FOXO1 is a direct target of miR-300 (Fig. 5A). To verify that FOXO1 is a target of miR-300, we analyzed the association between miR-300 and FOXO1. Co-transfection with miR-300 significantly decreased FOXO1 luciferase reporter activity (Fig. 5B, one-way ANOVA, $\mathrm{P}<0.05)$, while co-transfection with a miR-300 inhibitor had the opposite effect (Fig. 5C, one-way ANOVA, $\mathrm{P}<0.05)$. When the reporter gene carrying the mutated FOXO1 was co-transfected into the cells, the effect on luciferase activity was eliminated (Fig. 5B and C, one-way ANOVA test). miR-300 overexpression downregulated FOXO1 protein levels in MHCC-97L cells. Conversely, miR-300 downregulation increased FOXO1 levels in HCCLM3 and MHCC-97H cells (Fig. 5D and E). Moreover, a linear correlation analysis showed that FOXO1 expression was inversely proportional to miR-300 expression (Fig. 5F). Collectively, these data suggest that miR-300 exerts its effects on HCC by directly suppressing FOXO1.

The AKT/FOXO1 and AKT/mTOR pathways contribute to the maintenance of a miR-300-mediated malignant phenotype in HCC cells. Next, we detected the effect of the 


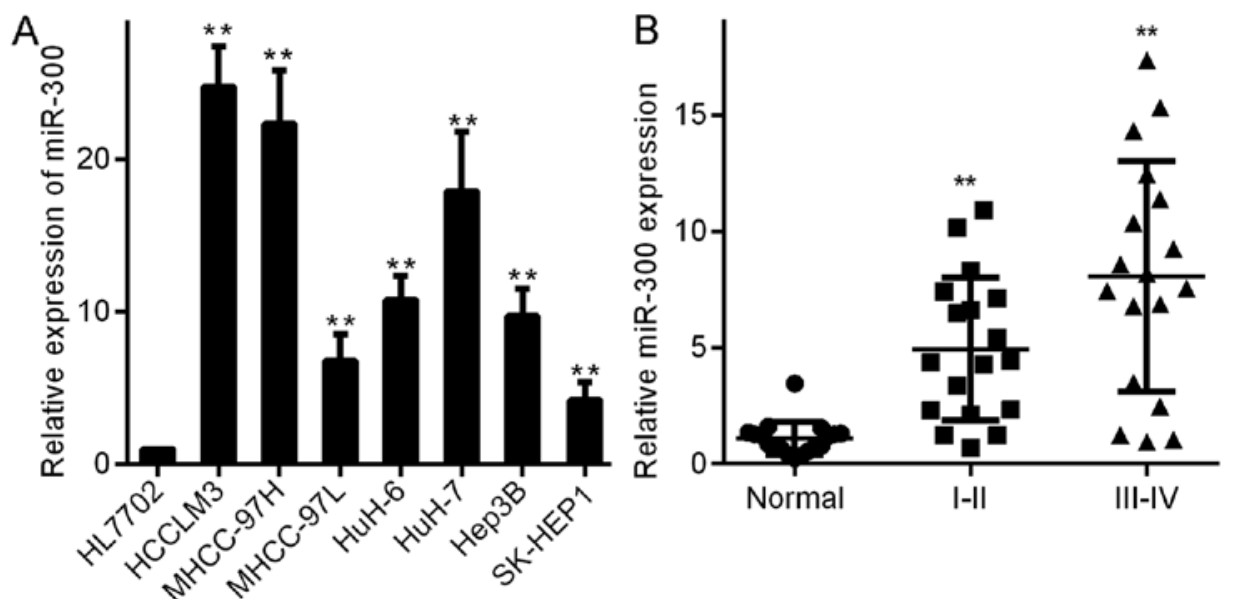

Figure 1. miR-300 is upregulated in HCC and liver cancer cells and human HCC tissues and is inversely correlated with patient survival. (A) Quantification of miR-300 expression showed that miR-300 levels are higher in HCC and liver cancer cell lines (HCCLM3, MHCC-97H, MHCC-97L, HuH-6, HuH-7, Hep3B and SK-HEP1) than that noted in the normal liver cell line (HL7702). (B) Quantification of miR-300 levels in the normal liver, stage I-II HCC and stage III-IV HCC tissues. ${ }^{* *} \mathrm{P}<0.01$ based on analysis of variance (ANOVA) analysis. Error bars, SD. HCC, hepatocellular carcinoma.

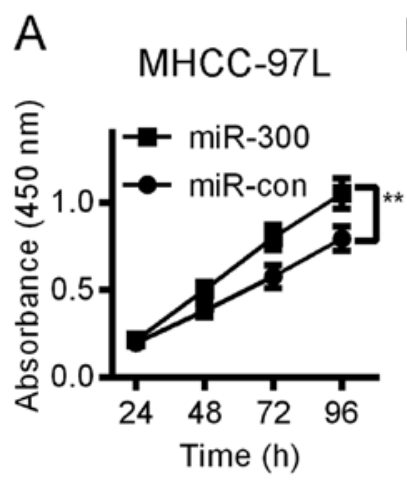

C
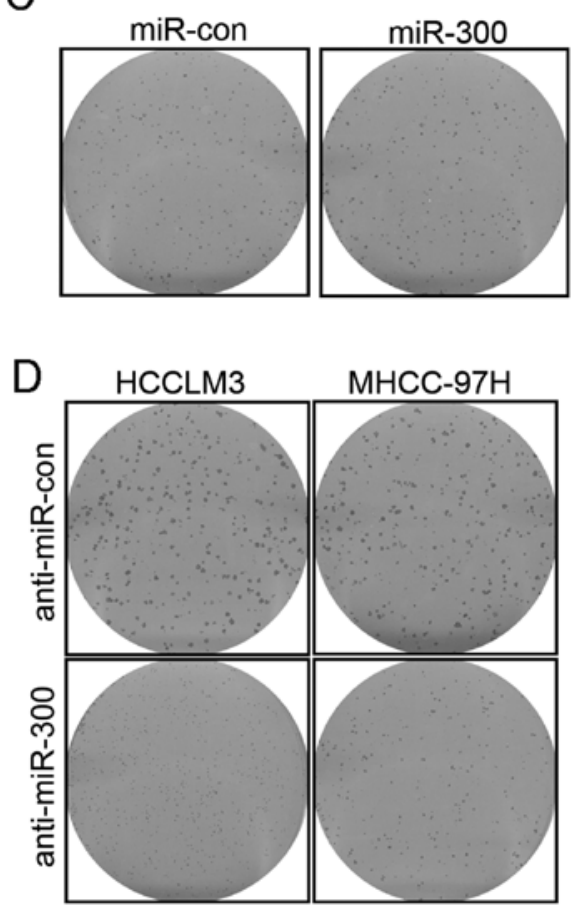

B

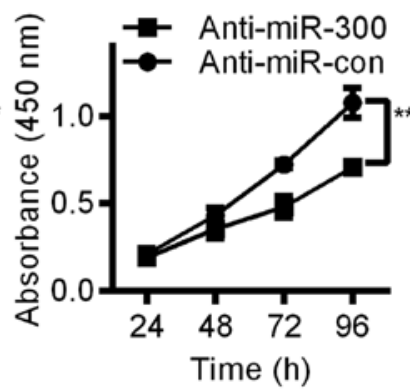

MHCC-97H
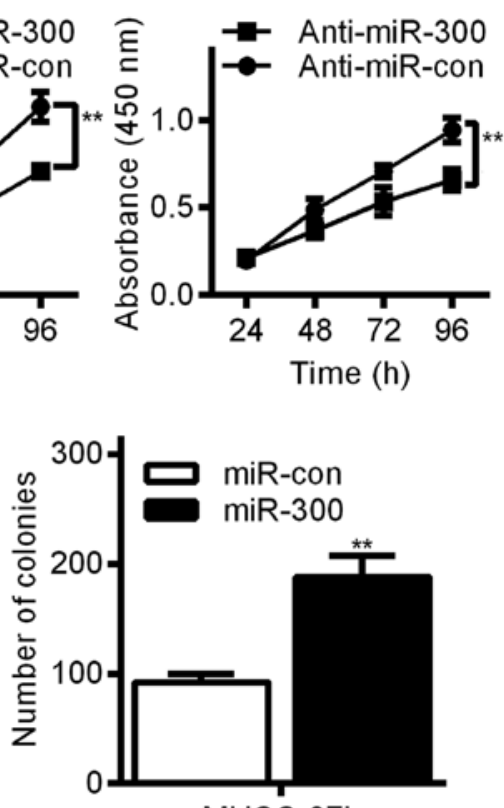

MHCC-97L

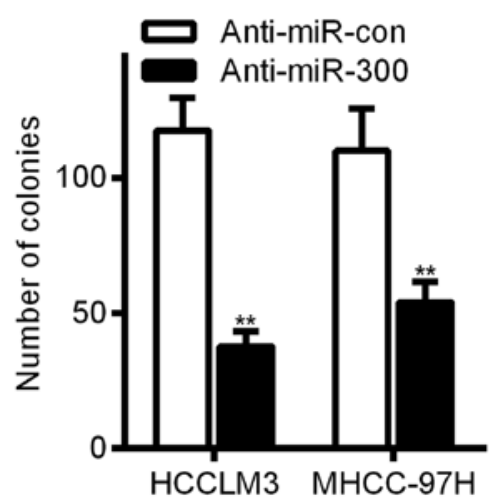

Figure 2. Ectopic expression of miR-300 increases the viability of HCC cells. (A) MTT assays were used to determine the growth curves for MHCC-97L cells. (B) MTT assays showing the growth curves for HCCLM3 and MHCC-97H cells. (C) Representative micrographs of crystal violet-stained cell colonies were analyzed using colony formation assays. MHCC-97L cells were incubated for 10 days. (D) Representative micrographs of crystal violet-stained cell colonies were analyzed using colony formation assays in HCCLM3 and MHCC-97H cells after 10 days. ${ }^{* *} \mathrm{P}<0.01$ based on Student's t-test. Error bars, SD. HCC, hepatocellular carcinoma. 

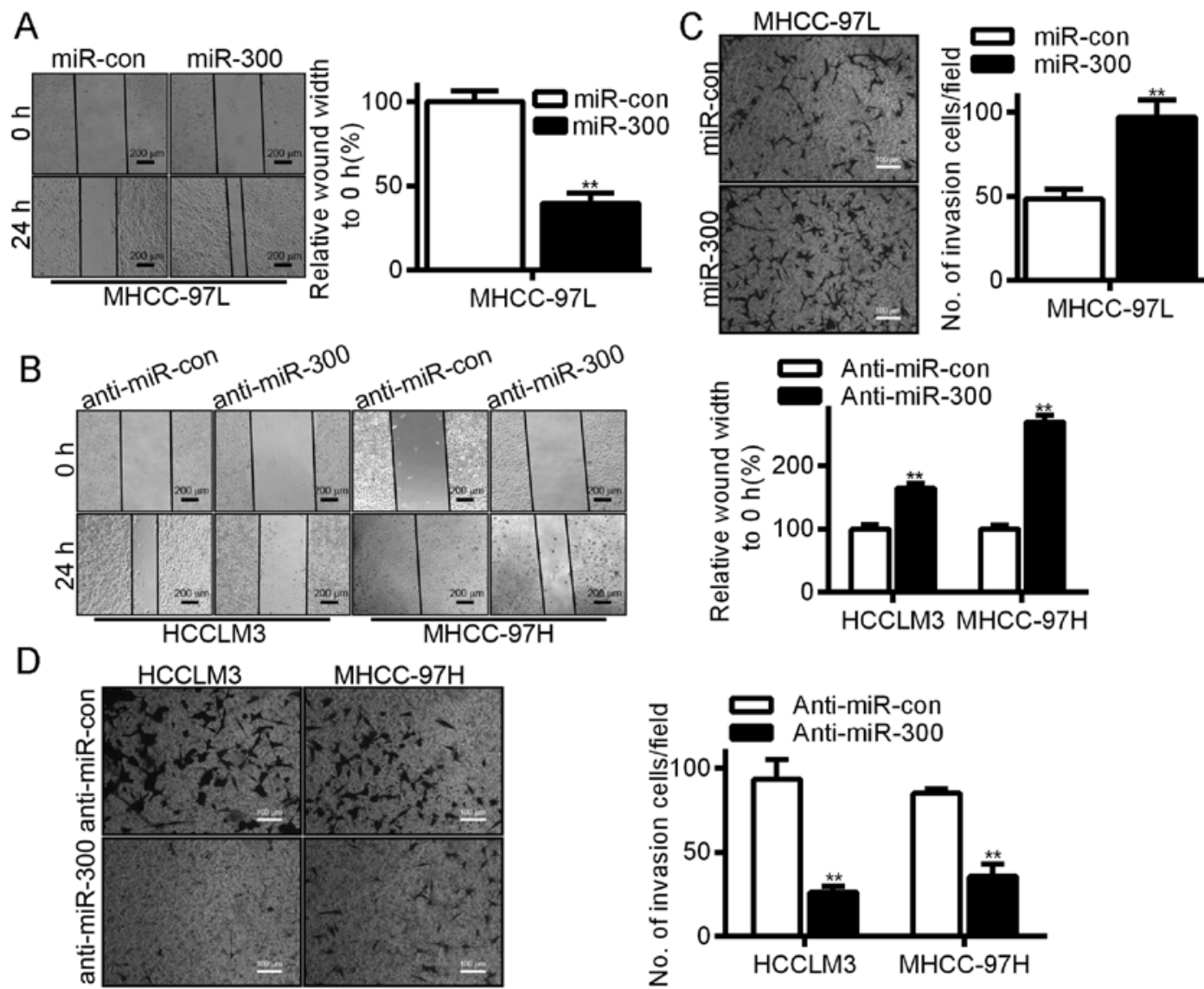

Figure 3. miR-300 overexpression promotes migration and invasion in HCC cells by wound healing and Transwell assays. (A) HCC cell lines were transfected with miR-300, and migration was assessed with a wound healing assay. (B) HCC cell lines were transfected with anti-miR-300, and migration was analyzed with a wound healing assay. (C) Representative results showing the invasiveness of MHCC-97L cells transfected with miR-300 or miR-con. (D) Representative results showing the invasiveness of HCCLM3 and MHCC-97H cells transfected with anti-miR-300 or anti-miR-con. * P $<0.01$ based on Student's t-test. Error bars, SD. HCC, hepatocellular carcinoma.

A
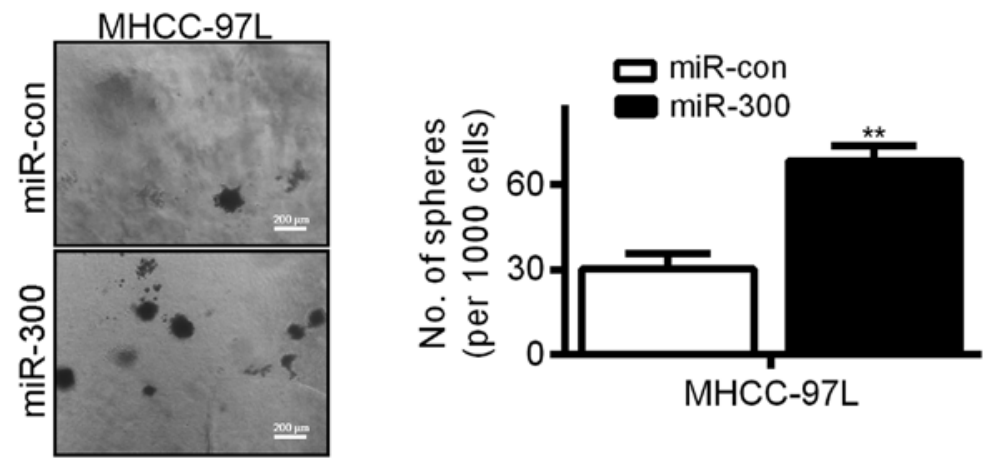

B
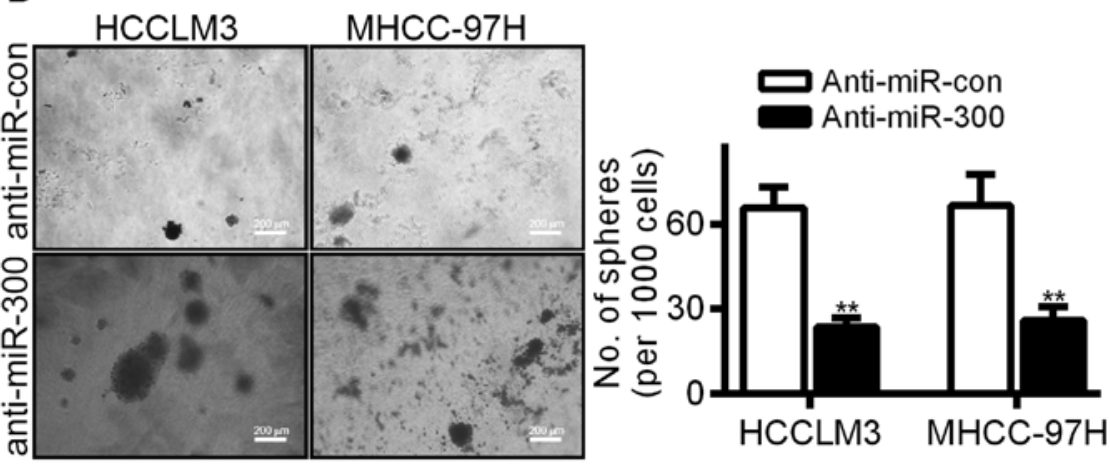

Figure 4. Ectopic miR-300 expression in HCC cells accelerates sphere formation. (A) Representative results of sphere formation assays in MHCC-97L cells transfected with miR-300 or miR-con. (B) Representative results of sphere formation assays in HCCLM3 and MHCC-97H cells transfected with anti-miR-300 or miR-con. ${ }^{* *} \mathrm{P}<0.01$ based on Student's t-test. Error bars, SD. HCC, hepatocellular carcinoma. 
A

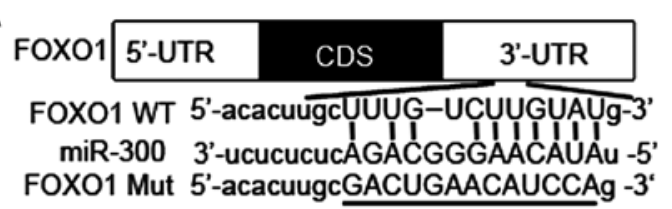

D

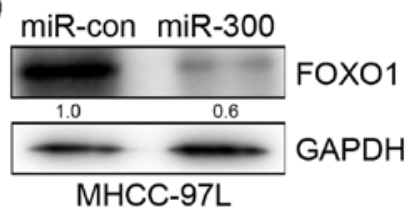

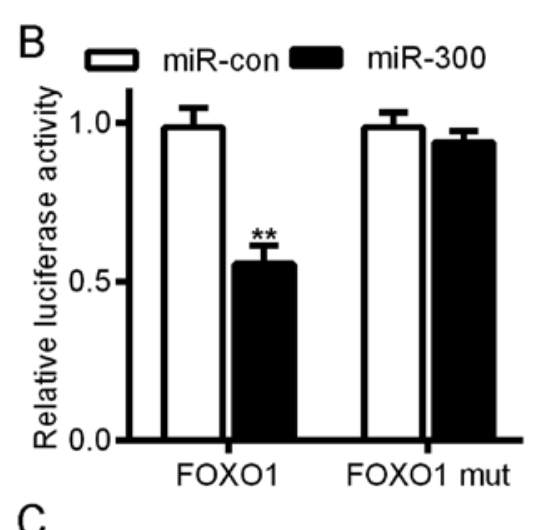

C

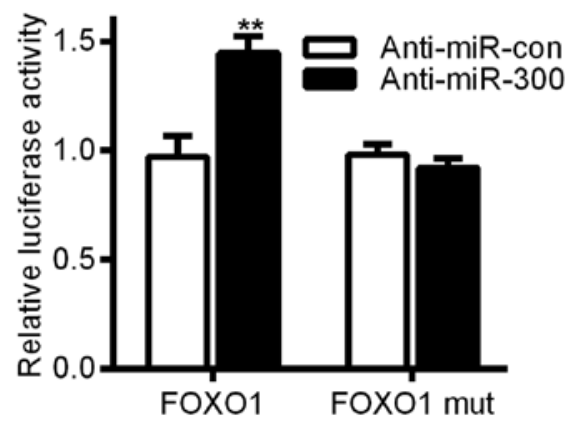

E
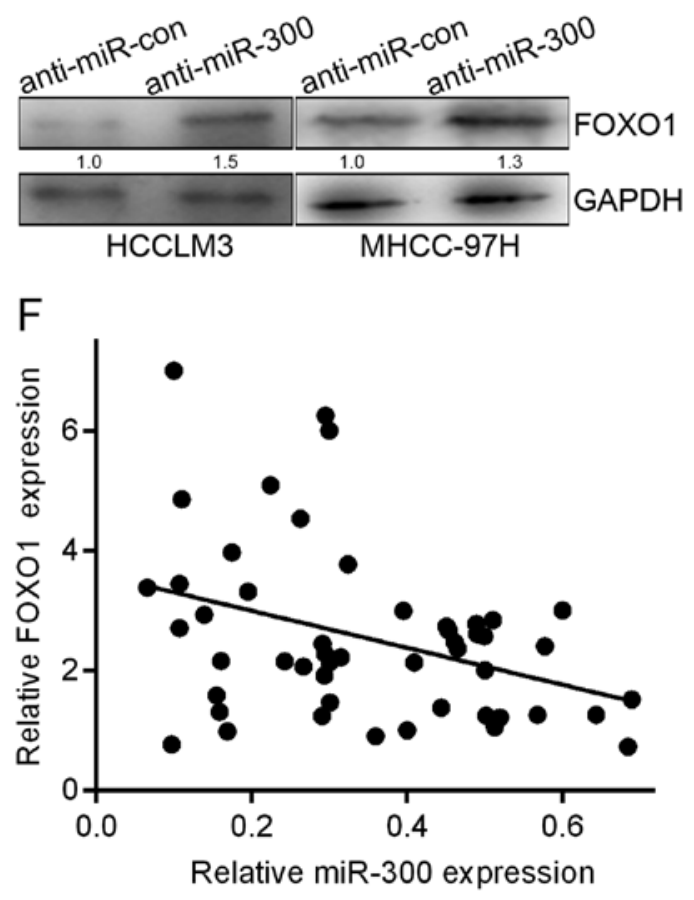

Figure 5. FOXO1 is a direct target of miR-300. (A) Wild-type (WT) miR-300 target sequences of FOXO1 3'-UTR and the mutant (Mut)-type miR-300 target sequences of the FOXO1 3'-UTR. (B and C) Relative luciferase activity of FOXO1 in cells that were co-transfected with the WT or Mut FOXO1 3'-UTR reporter genes and miR-300, anti-miR-300 or the control. (D) FOXO1 expression was assayed by western blot analysis in miR-300-overexpressing cells. (E) FOXO1 expression was assayed by western blot analysis in miR-300-silenced cells. (F) The correlation between miR-300 overexpression and FOXO1 downregulation was evaluated in the indicated HCC tissues. ${ }^{* *} \mathrm{P}<0.01$ based on Student's t-test. Error bars, SD. HCC, hepatocellular carcinoma.

miR-300-mediated inhibition of FOXO1 on the maintenance of malignant phenotypes in HCC cells. Notably, overexpression of miR-300 significantly increased the expression levels of phosphorylated AKT, leading to an increase in the expression levels of phosphorylated S6K and 4E-BP1 (Fig. 6A), while inhibiting miR-300 in HCCLM3 cells strongly inhibited AKT, S6K and 4E-BP1 expression (Fig. 6B), suggesting that miR-300 activated the AKT/FOXO1 and AKT/mTOR signaling pathways. Accordingly, SNAIL and MMP2 were found to promote tumor invasion and metastasis in HCC (22). As shown, the increased expression of the MMP2 and SNAIL proteins (Fig. 6C) may have been caused by miR-300 overexpression; when miR-300 was knocked down in HCCLM3 cells, MMP2 and SNAIL protein expression was downregulated (Fig. 6D). In addition, the phosphorylation of AKT, S6K and 4E-BP1 was increased in tumor cells overexpressing miR-300 (Fig. 6E). To confirm that AKT/FOXO1 and AKT/mTOR pathway activation is involved in the effects of miR-300, we used specific inhibitors of each signaling pathway in our subsequent experiments. The results indicated that LY294002 (20 $\mu \mathrm{mol} / \mathrm{l})$, a P13K inhibitor, significantly reduced the phosphorylation of P13K and Akt (Fig. 7A), while the AKT inhibitor $(6 \mu \mathrm{mol} / \mathrm{l})$ reduced the phosphorylation of Akt but not P13K (Fig. 7B). Rapamycin $(2 \mu \mathrm{mol} / \mathrm{l})$, an inhibitor of the mTOR pathway, reduced the phosphorylation of S6K and 4E-BP1 (Fig. 7C). In addition, all three types of inhibitors reduced the growth of miR-300-overexpressing cells (Fig. 7D-F). These results indicate that miR-300 promotes a proliferative phenotype in HCC cells by activating the AKT/FOXO1 and AKT/mTOR signaling pathways.

Suppression of FOXO1 in liver cancer cells is essential for miR-300-induced viability. To investigate the indispensable role of FOXO1 in miR-300-mediated biological functions, we silenced FOXO1 in HCCLM3-anti-miR300 cells (Fig. 8A). The results as shown in Fig. 8A indicated that ectopic knockdown of FOXO1 increased the phosphorylation of S6K and 4E-BP1 in HCCLM3-anti-miR-300 cells (Fig. 8A). In subsequent functional experiments, silencing of FOXO1 in anti-miR-300 cells significantly induced cell viability and clone formation in soft agar (Fig. 8B) and wound healing assays (Fig. 8C). In addition, silencing of FOXO1 promoted the invasiveness of HCCLM3 cells transfected with miR-300 (Fig. 8D). These data indicate that FOXO1 plays a key role in miR-300-induced viability, migration and invasion.

miR-300-overexpressing cells and control cells were subcutaneously inoculated into thymic Balb/C mice to evaluate the function of miR-300 to confirm whether its 
A

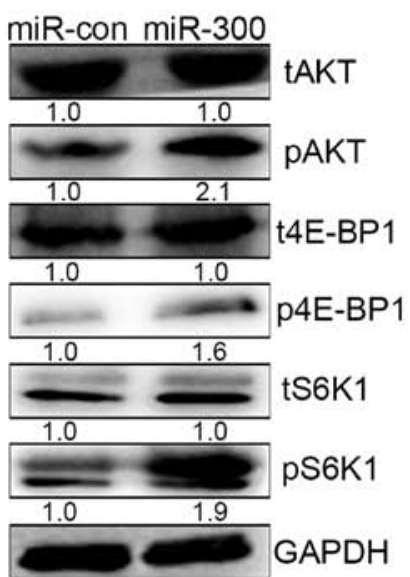

$\mathrm{E}$

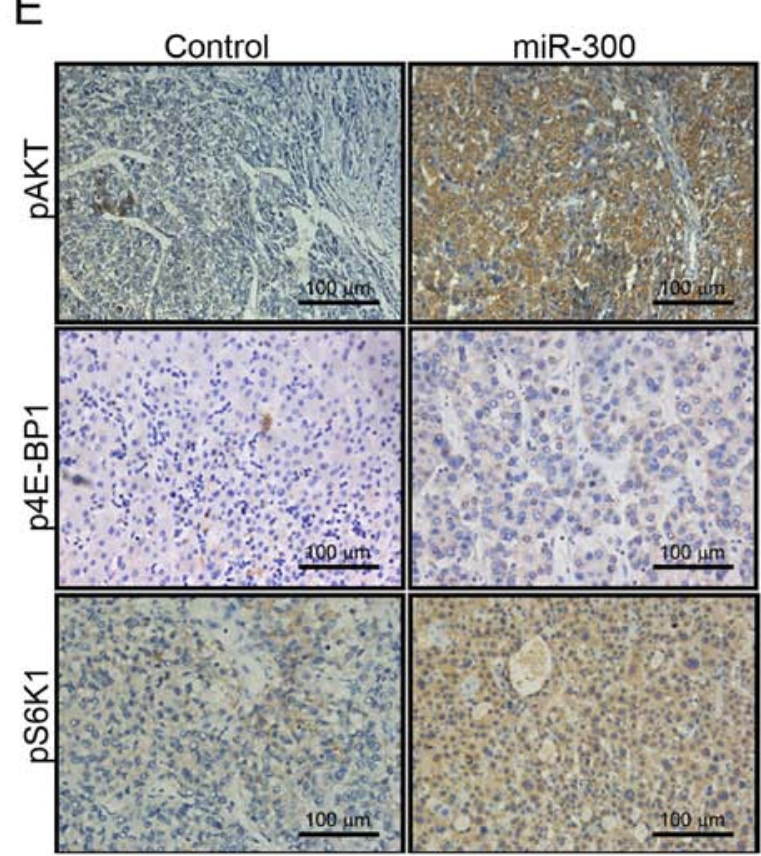

B

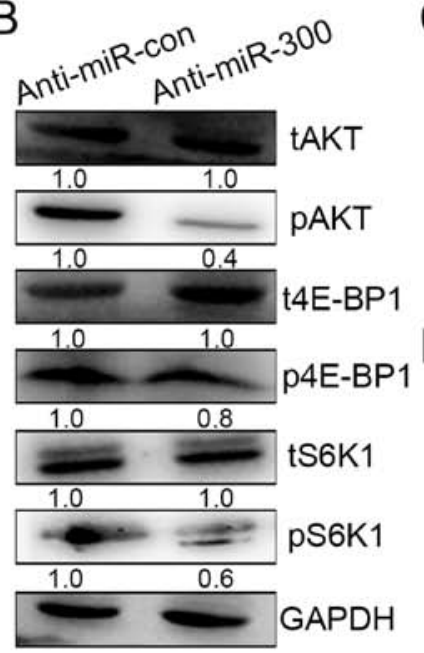

C
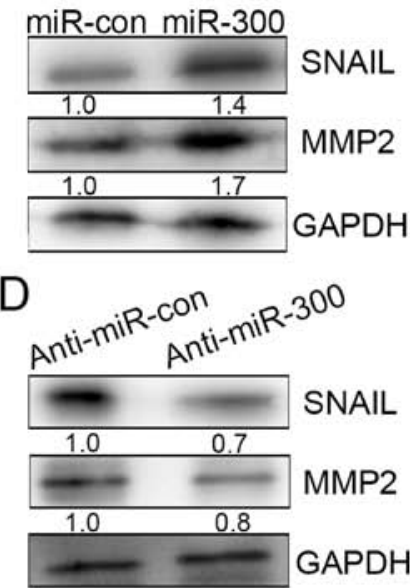
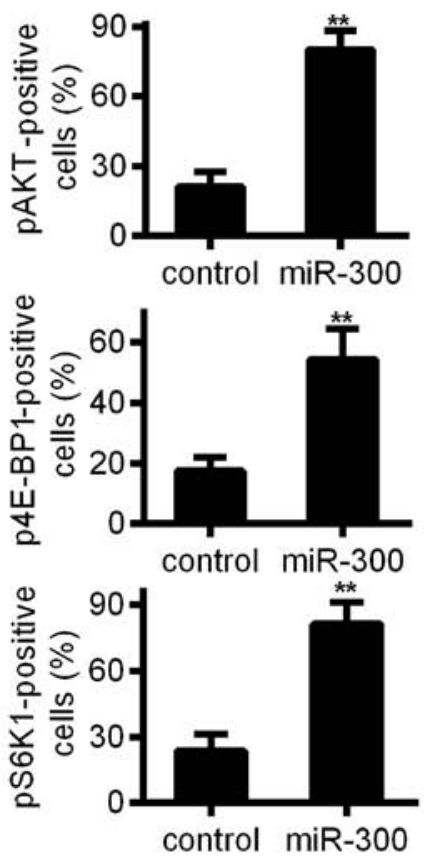

Figure 6. miR-300 activates both the AKT/FOXO1 and AKT/mTOR signaling pathways. (A and B) Western blot analysis of phospho-AKT (pAKT), total AKT (tAKT), phospho-S6K1 (pS6K1), total S6K1 (tS6K1), phospho-4E-BP1 (p4E-BP1), and total 4E-BP1 (t4E-BP1) levels in the indicated cell lines. (C and D) Quantified protein expression of SNAIL and MMP2 in the indicated cell lines. (E) IHC analysis of pAKT, p4E-BP1 and pS6K1 expression in miR-300-overexpressing tumors. ${ }^{* *} \mathrm{P}<0.01$ based on Student's t-test. Error bars, SD. IHC, immunohistochemistry.

growth-promoting effect in vitro was related to liver cancer growth in vivo. As shown in Fig. $9 \mathrm{~A}$ and $\mathrm{B}$, in the in vivo assays, miR-300 overexpression significantly contributed to tumor growth and increases in tumor weight (Fig. 9B) and tumor volume (Fig. 9C). Based on these results, we concluded that miR-300 promotes the viability of liver cancer cells both in vivo and in vitro.

\section{Discussion}

Many studies have indicated that aberrant miRNA expression contributes to the progression and development of cancers, including HCC (23). miRNAs have become novel prognostic biomarkers for and effective therapeutic targets in HCC (24). This study provides initial data showing that miR-300 expression is increased in $\mathrm{HCC}$ cell lines and tissues and that in HCC, invasiveness and the risk of relapse are associated with a higher level of miR-300 expression. These results indicated that miR-300 plays an important role in promoting tumor functions in HCC.

More recently, many studies have demonstrated that miRNAs play important roles in maintaining normal cellular functions and that disorders of miRNA expression can lead to cancer progression (25). In this study, we investigated the expression and function of miR-300 in HCC and liver cancer cells. We also explored the molecular mechanisms underlying the effects of miR-300 to gain a better understanding of its roles, and we found that the AKT/FOXO1 and AKT/mTOR signaling pathways contributed to the malignant phenotype observed in miR-300-overexpressing HCC cells and that the 

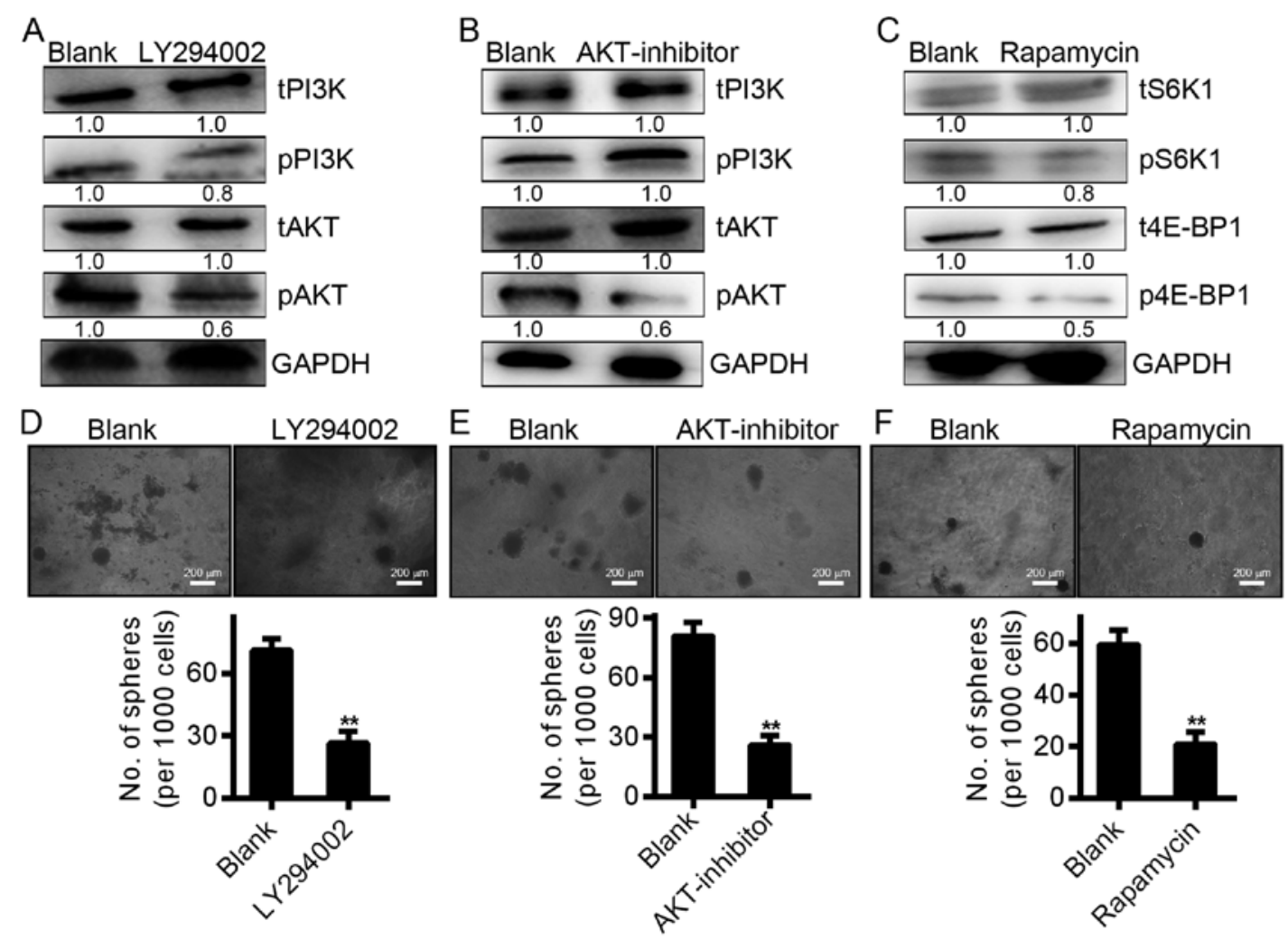

Figure 7. The AKT/FOXO1 and AKT/mTOR signaling pathway inhibitors each restrained the growth of miR-300-overexpressing cells. (A-C) Western blot analysis showing the effects of LY294002, AKT inhibitor and rapamycin on miR-300-overexpressing cells. (D-F) Soft agar assays showing the effects of LY294002, AKT inhibitor and rapamycin on miR-300-overexpressing cells. ${ }^{* *} \mathrm{P}<0.01$ based on Student's t-test. Error bars, SD.
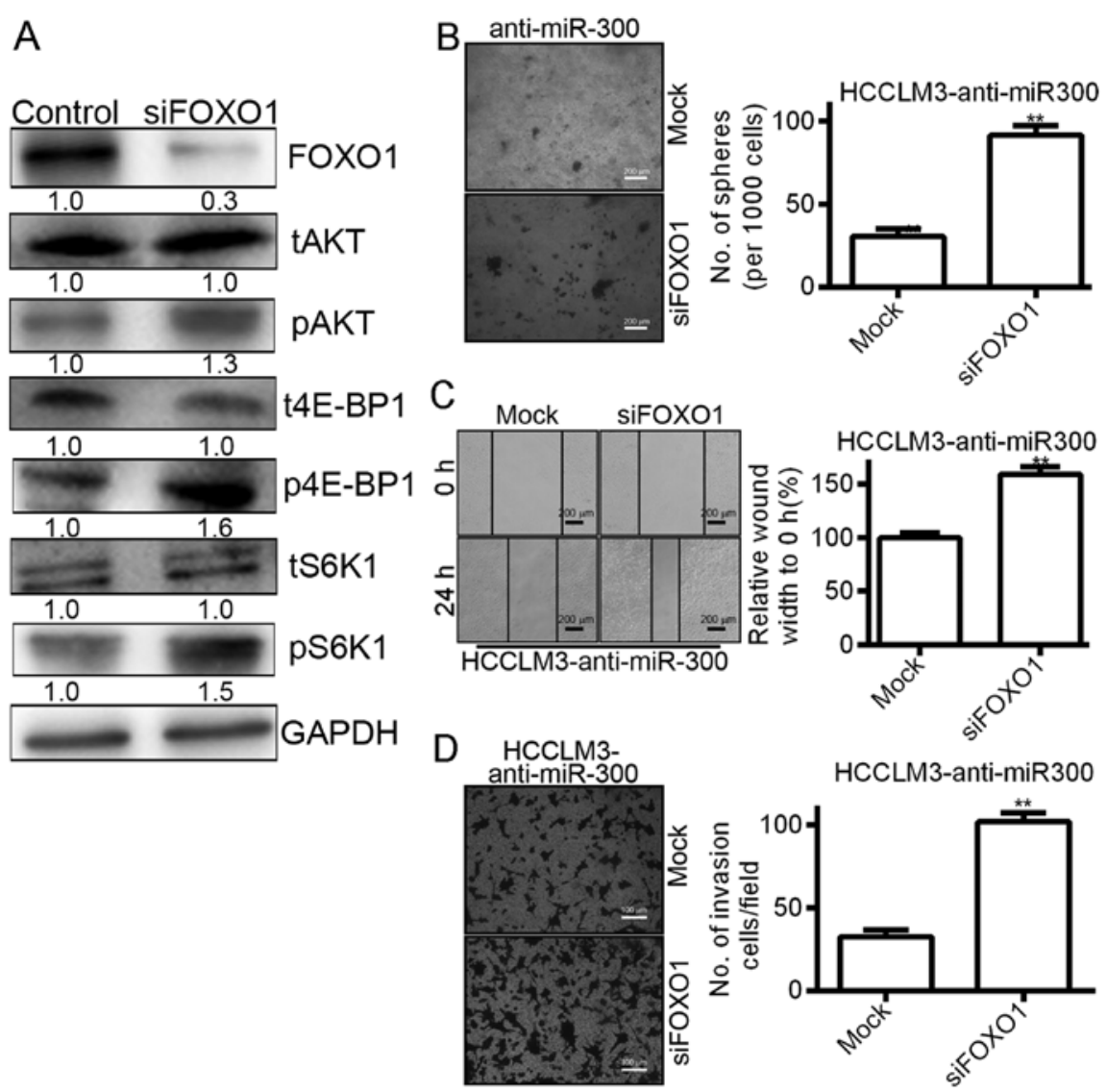

Figure 8. Restoration of FOXO1 expression reverses miR-300-induced viability and invasion through soft agar, wound healing and Transwell assays. (A and B) The results of the western blot analysis confirmed the re-expression or depletion of FOXO1 in the indicated cells. (C) Soft agar analysis of HCC cells after the re-expression or depletion of FOXO1. (D) Wound healing assays showing the effect of re-expressing or depleting FOXO1 on the indicated cell lines. (E) Transwell assay showing the effect of re-expressing or depleting FOXO1 on the indicated cells. ${ }^{* *} \mathrm{P}<0.01$ based on Student's t-test. Error bars, SD. 


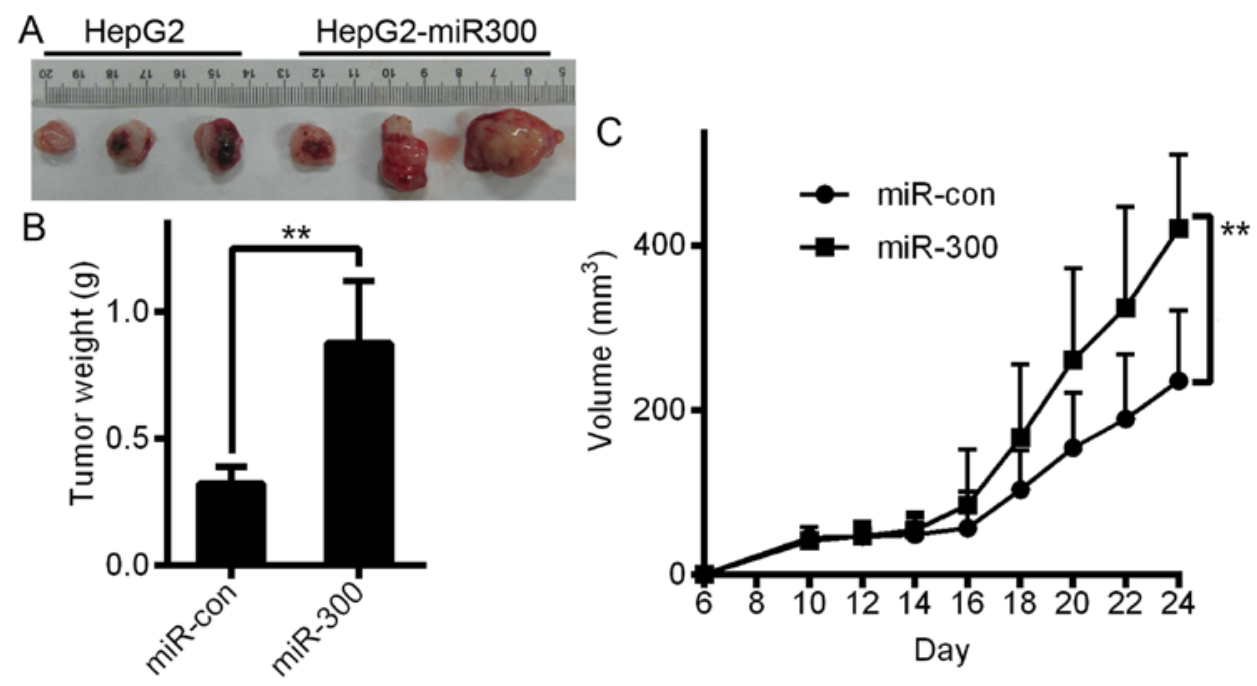

Figure 9. miR-300 suppresses the tumor growth of liver cancer HepG2 cells in vivo. (A) HepG2 cells stably overexpressing miR-300 or a scrambled miR-con were subcutaneously injected into nude mice. A representative image of the tumors that formed after 22 days is shown. (B) Tumor weight. (C) The tumor volumes were larger in the tumors derived from the HepG2 cells stably overexpressing miR-300 than in the control cells. The data are presented as the mean \pm SD. ${ }^{* *} \mathrm{P}<0.01$ based on Student's-test. Error bars, SD.

specific mechanism responsible for this effect may involve the inhibition of FOXO1 expression. It is noteworthy that there was a strong correlation between high miR-300 expression and low FOXO1 expression and the malignant nature of HCC in both implanted tumors and clinical HCC samples. These data collectively demonstrate that miR-300 affects the development of HCC.

FOXO1 is a member of the FOXO subfamily of transcription factors and acts as a tumor suppressor and regulates genes involved in apoptotic responses, cell cycle checkpoints and cellular metabolism. A number of studies indicate that FOXO1 expression is decreased in various types of cancer tissues compared with normal tissues. However, the mechanism of aberrant FOXO1 expression is poorly understood. Recent studies have shown that post-transcriptional regulation plays a key role in the downregulation of FOXO1 and the modulation of its activity. miR-300 has been shown to play an anti-apoptotic role in bladder and prostate cancer by targeting the 3'-UTR of FOXO1 to reduce its expression. The transcription factor FOXO1 is expressed in a variety of species and belongs to a subfamily of Forkhead protein family class $\mathrm{O}$ transcription factors. FOXO1 exerts its tumor-suppressive function by modulating the transcription of important regulators of the cell cycle and apoptosis (26-28), and previous studies support the notion that FOXO1 functions as a tumor suppressor by demonstrating its role in the regulation of cell cycle progression and cell differentiation, metabolism and survival (28). Furthermore, lower levels of FOXO1 expression have been observed in many tumor types, such as Hodgkin lymphoma (29) and breast cancer (30). FOXO1 transcriptional activity is regulated by the PI3K/AKT signaling pathway (31), and FOXO1 is downregulated in prostate cancer by several molecular mechanisms. As previously reported, FOXO1 activity is inhibited by Akt signaling pathway hyperactivity, which occurs in up to $50 \%$ of all prostate cancers, primarily as a result of a PTEN deletion (32). Furthermore, the locus of FOXO1 on chromosome 13q14 is deleted in patients with prostate cancer (33). Our results indicated that FOXO1 is regulated by an alternate mechanism in which its 3 '-UTR is bound by miR-300.

FOXO1 belongs to a subfamily of forkhead transcription factors that contain a conserved forkhead DNA-binding domain (34). FOXO subfamily members participate in various signaling pathways and regulate many biochemical processes, such as cell cycle progression, cell differentiation and the cell apoptosis (35-37). FOXO1 is a tumor suppressor, and FOXO1 downregulation has been implicated in tumor function $(29,33)$. Since FOXO is a downstream target of the serine/threonine protein kinase B (PKB)/Akt signaling pathway, FOXO1 inhibition results from high expression of $\mathrm{Akt}$, whose activation induces the phosphorylation of FOXO1, which causes the tumor suppressor to translocate from the nucleus to the cytoplasm, where it is subsequently degraded.

Ichiyama et al reported that FOXO1 is one of the targets of the microRNA-183-96-182 cluster. miR-183C drives Th17 pathogenicity in autoimmune diseases by inhibiting FOXO1 (38). Furthermore, two miRNAs, miR-96 and miR-370, target FOXO1 and regulate its expression in prostate cancer cells. Suppressing these miRNAs was found to increase FOXO1 protein levels and decrease cell viability $(39,40)$. Our study showed that FOXO1 is a direct target of miR-300, which downregulated FOXO1 expression in vitro, as shown by the luciferase experiment. These results indicated that in addition to the known mechanisms that regulate FOXO1 expression, other mechanisms (e.g., the epigenetic regulation of miRNAs) regulate FOXO1 expression. The regulation of FOXO1 by specific miRNAs plays an important role in tumor progression.

It is important to determine whether miR-300 and FOXO1 are useful as biomarkers for diagnostic assays. Our results indicated that high miR-300 expression levels and low FOXO1 expression levels are associated with poor clinical features in patients with HCC. Furthermore, the results demonstrated that high miR-300 expression, FOXO1 downregulation, and a 
combination of both are significantly associated with a poor prognosis in patients with HCC. Our results also indicated that miR-300 and FOXO1 are promising prognostic indicators in patients with HCC.

To test our hypothesis independently of patient samples, we decided to perform cell-based assay. Based on our results, liver cancer HepG2 cells exhibited a lower miRNA-300 level. In the last few decades, the HepG2 cell line was considered HCC. However, the HepG2 cell line has been reported to be misidentified. López-Terrada et al, who initially isolated these cells, recently corrected their report and claimed that HepG2 cells should in fact be considered a hepatoblastoma cell line (41). To exclude the misleading effect of cytological background on the conclusion, we used MHCC-97L cells as a parallel group. Our results of HepG2 and MHCC-97L cells in vitro were similar (data not shown). Therefore, we selected the human liver cancer HepG2 cell line for the in vivo experiment, although it has hepatoblastoma characteristics. The aforementioned misidentification issue is unlikely to affect the outcome of our study.

In conclusion, our results indicate that FOXO1 is downregulated by miR-300 in HCC cells and that FOXO1 mediates miR-300-induced cell viability. In addition, pAKT, p4E-BP1, pS6K1, SNAIL and MMP2 expression was found to be dysregulated in miR-300-overexpressing HCC cells, indicating that miR-300 levels are correlated with PI3K/AKT signaling pathway activity. In this study, the results of the gain-of-expression and functional loss-of-expression experiments confirmed that overexpression of miR-300 promoted HCC cell migration and invasion, whereas knockdown of miR-300 inhibited these metastatic behaviors both in vitro and in vivo.

\section{Acknowledgements}

Not applicable.

\section{Funding}

The present study was supported by the Scientific and Technological Project Foundation of Xi'an City [2017113SFYX007(6)], the Scientific and Technological Development Research Project Foundation of Shaanxi Province (2016SF-121) and the Fundamental Research Funds for the Central Universities of Xi'an Jiaotong University.

\section{Availability of data and materials}

The datasets used during the present study are available from the corresponding author upon reasonable request.

\section{Authors' contributions}

YC, XL, LF and XC conceived and designed the study. YC, $\mathrm{CZ}, \mathrm{GQ}, \mathrm{GWa}$ and GWe performed the experiments. YC, XL, $\mathrm{LF}$ and $\mathrm{XC}$ analyzed the data. YC and XL wrote the paper. LF and XC reviewed and edited the manuscript. All authors read and approved the manuscript and agree to be accountable for all aspects of the research in ensuring that the accuracy or integrity of any part of the work are appropriately investigated and resolved.

\section{Ethics approval and consent to participate}

Ethical approval for the study using human tissues was obtained from the First Affiliated Hospital Ethics Committee of Xi'an Jiaotong University. All participants provided written informed consent. The animal experiment was conducted at the Xi'an Jiaotong University Experimental Research Laboratory with the consent of the Experimental Animal Ethics Committ ee (No. XJTULAC2018-450).

\section{Patient consent for publication}

Not applicable.

\section{Competing interests}

The authors declare that there are no competing interests related to this study.

\section{References}

1. El-Serag HB and Rudolph KL: Hepatocellular carcinoma: Epidemiology and molecularcarcinogenesis.Gastroenterology 132: 2557-2576, 2007.

2. Torre LA, Bray F, Siegel RL, Ferlay J, Lortet-Tieulent J and Jemal A: Global cancer statistics, 2012. CA Cancer J Clin 65: 87-108, 2015.

3. Maluccio M and Covey A: Recent progress in understanding, diagnosing, and treating hepatocellular carcinoma. CA Cancer J Clin 62: 394-399, 2012.

4. Altomare DA and Testa JR: Perturbations of the AKT signaling pathway in human cancer. Oncogene 24: 7455-7464, 2005.

5. Cui SX, Shi WN, Song ZY, Wang SQ, Yu XF, Gao ZH and Qu XJ: Des-gamma-carboxy prothrombin antagonizes the effects of Sorafenib on human hepatocellular carcinoma through activation of the Raf/MEK/ERK and PI3K/Akt/mTOR signaling pathways. Oncotarget 7: 36767-36782, 2016.

6. Bartel DP: MicroRNAs: Genomics, biogenesis, mechanism, and function. Cell 116: 281-297, 2004.

7. He L and Hannon GJ: MicroRNAs: Small RNAs with a big role in gene regulation. Nat Rev Genet 5: 522-531, 2004.

8. Liu Z, Dou C, Yao B, Xu M, Ding L, Wang Y, Jia Y, Li Q, Zhang $\mathrm{H}, \mathrm{Tu} \mathrm{K}$, et al: Methylation-mediated repression of microRNA-129-2 suppresses cell aggressiveness by inhibiting high mobility group box 1 in human hepatocellular carcinoma. Oncotarget 7: 36909-36923, 2016.

9. Yang W, Dou C, Wang Y, Jia Y, Li C, Zheng X and Tu K: MicroRNA-92 a contributes to tumor growth of human hepatocellular carcinoma by targeting FBXW7. Oncol Rep 34: 2576-2584, 2015.

10. Lu CY, Lin KY, Tien MT, Wu CT, Uen YH and Tseng TL: Frequent DNA methylation of MiR-129-2 and its potential clinical implication in hepatocellular carcinoma. Genes Chromosomes Cancer 52: 636-643, 2013.

11. Furuta M, Kozaki KI, Tanaka S, Arii S, Imoto I and Inazawa J: miR-124 and miR-203 are epigenetically silenced tumor-suppressive microRNAs in hepatocellular carcinoma. Carcinogenesis 31: 766-776, 2010.

12. Liu Y, Ren F, Rong M, Luo Y, Dang Y and Chen G: Association between underexpression of microrna-203 and clinicopathological significance in hepatocellular carcinoma tissues. Cancer Cell Int 15: 62, 2015.

13. Alpini G, Glaser SS, Zhang JP, Francis H, Han Y, Gong J, Stokes A, Francis T, Hughart N, Hubble L, et al: Regulation of placenta growth factor by microRNA-125b in hepatocellular cancer. J Hepatol 55: 1339-1345, 2011.

14. Coulouarn C, Factor VM, Andersen JB, Durkin ME and Thorgeirsson SS: Loss of miR-122 expression in liver cancer correlates with suppression of the hepatic phenotype and gain of metastatic properties. Oncogene 28: 3526-3536, 2009. 
15. Gramantieri L, Ferracin M, Fornari F, Veronese A, Sabbioni S, Liu CG, Calin GA, Giovannini C, Ferrazzi E, Grazi GL, et al: Cyclin G1 is a target of miR-122a, a microRNA frequently down-regulated in human hepatocellular carcinoma. Cancer Res 67: 6092-6099, 2007.

16. Lin CJ, Gong HY, Tseng HC, Wang WL and Wu JL: miR-122 targets an anti-apoptotic gene, Bcl-w, in human hepatocellular carcinoma cell lines. Biochem Biophys Res Commun 375 315-320, 2008

17. Greer EL and Brunet A: FOXO transcription factors at the interface between longevity and tumor suppression. Oncogene 24: 7410-7425, 2005

18. Hartmann W, Küchler J, Koch A, Friedrichs N, Waha A, Endl E, Czerwitzki J, Metzger D, Steiner S, Wurst P, et al: Activation of phosphatidylinositol-3'-kinase/AKT signaling is essential in hepatoblastoma survival. Clin Cancer Res 15: 4538-4545, 2009.

19. Nogueira V, Park Y, Chen CC, Xu PZ, Chen ML, Tonic I, Unterman $\mathrm{T}$ and Hay $\mathrm{N}$ : Akt determines replicative senescence and oxidative or oncogenic premature senescence and sensitizes cells to oxidative apoptosis. Cancer Cell 14: 458-470, 2008.

20. Gospodarowicz MK, Brierley JD and Wittekind C (eds): TNM classifcation of malignant tumours. 8th edition. John Wiley \& Sons, Oxford, UK, 2017.

21. Sinicrope FA, Ruan SB, Cleary KR, Stephens LC, Lee JJ and Levin B: Bcl-2 and p53 oncoprotein expression during colorectal tumorigenesis. Cancer Res 55: 237-241, 1995.

22. Miyoshi A, Kitajima Y, Sumi K, Sato K, Hagiwara A, Koga Y and Miyazaki K: Snail and SIP1 increase cancer invasion by upregulating MMP family in hepatocellular carcinoma cells. $\mathrm{Br}$ J Cancer 90: 1265-1273, 2004

23. Xiang ZL, Zhao XM, Zhang L, Yang P, Fan J, Tang ZY and Zeng ZC: MicroRNA-34a expression levels in serum and intratumoral tissue can predict bone metastasis in patients with hepatocellular carcinoma. Oncotarget 7: 87246-87256, 2016.

24. Dou C, Wang Y, Li C, Liu Z, Jia Y, Li Q, Yang W, Yao Y, Liu Q and Tu K: MicroRNA-212 suppresses tumor growth of human hepatocellular carcinoma by targeting FOXA1. Oncotarget 6: 13216-13228, 2015.

25. Calin GA and Croce CM: MicroRNA-cancer connection: The beginning of a new tale. Cancer Res 66: 7390-7394, 2006.

26. Machida S, Spangenburg EE and Booth FW: Forkhead transcription factor FoxO1 transduces insulin-like growth factor's signal to p27Kip1 in primary skeletal muscle satellite cells. J Cell Physiol 196: 523-531, 2003.

27. Kim SJ, Winter K, Nian C, Tsuneoka M, Koda Y and McIntosh CH: Glucose-dependent insulinotropic polypeptide (GIP) stimulation of pancreatic beta-cell survival is dependent upon phosphatidylinositol 3-kinase (PI3K)/protein kinase B (PKB) signaling, inactivation of the forkhead transcription factor Foxol, and down-regulation of bax expression. J Biol Chem 280 22297-22307, 2005
28. Grinius L, Kessler C, Schroeder J and Handwerger S: Forkhead transcription factor FOXO1A is critical for induction of human decidualization. J Endocrinol 189: 179-187, 2006.

29. Xie L, Ushmorov A, Leithäuser F, Guan H, Steidl C, Färbinger J, Pelzer C, Vogel MJ, Maier HJ, Gascoyne RD, et al: FOXO1 is a tumor suppressor in classical Hodgkin lymphoma. Blood 119: 3503-3511, 2012.

30. Wu Y, Elshimali Y, Sarkissyan M, Mohamed H, Clayton S and Vadgama JV: Expression of FOXO1 is associated with GATA3 and Annexin-1 and predicts disease-free survival in breast cancer. Am J Cancer Res 2: 104-115, 2012.

31. Rena G, Guo S, Cichy SC, Unterman TG and Cohen P: Phosphorylation of the transcription factor forkhead family member FKHR by protein kinase B. J Biol Chem 274: 17179-17183, 1999.

32. Morgan TM, Koreckij TD and Corey E: Targeted therapy for advanced prostate cancer: Inhibition of the PI3K/Akt/mTOR pathway. Curr Cancer Drug Targets 9: 237-249, 2009.

33. Dong XY, Chen C, Sun X, Guo P, Vessella RL, Wang RX, Chung LW, Zhou W and Dong JT: FOXO1A is a candidate for the 13q14 tumor suppressor gene inhibiting androgen receptor signaling in prostate cancer. Cancer Res 66: 6998-7006, 2006.

34. Calnan DR and Brunet A: The FoxO code. Oncogene 27: 2276-2288, 2008.

35. Huang $\mathrm{H}$ and Tindall DJ: FOXO factors: A matter of life and death. Future Oncol 2: 83-89, 2006.

36. Furukawa-Hibi Y, Yoshida-Araki K, Ohta T, Ikeda K and Motoyama N: FOXO forkhead transcription factors induce $\mathrm{G}_{2}-\mathrm{M}$ checkpoint in response to oxidative stress. J Biol Chem 277: 26729-26732, 2002.

37. Arden KC: FoxOs in tumor suppression and stem cell maintenance. Cell 128: 235-237, 2007.

38. Ichiyama K, Gonzalez-Martin A, Kim BS, Jin HY, Jin W, $\mathrm{Xu}$ W, Sabouri-Ghomi M, Xu S, Zheng P, Xiao C and Dong C: The MicroRNA-183-96-182 cluster promotes T helper 17 cell pathogenicity by negatively regulating transcription factor Foxo1 expression. Immunity 44: 1284-1298, 2016.

39. Haflidadóttir BS, Larne O, Martin M, Persson M, Edsjö A, Bjartell A and Ceder Y: Upregulation of miR-96 enhances cellular proliferation of prostate cancer cells through FOXO1. PLoS One 8: e72400, 2013.

40. Wu Z, Sun H, Zeng W, He J and Mao X: Upregulation of MircoRNA-370 induces proliferation in human prostate cancer cells by downregulating the transcription factor FOXO1. PLoS One 7: e45825, 2012.

41. López-Terrada D, Cheung SW, Finegold MJ and Knowles BB: Hep G2 is a hepatoblastoma-derived cell line. Hum Pathol 40: $1512-1515,2009$. 